\title{
Call centre employee's reasons for variation in objective productivity during a cognitive ergonomics intervention.
}

\author{
Silvia Ahmed \\ School of Design and Creative Arts, Loughborough University, e-mail: S.Ahmed2@lboro.ac.uk \\ Michael Fray \\ School of Design and Creative Arts, Loughborough University, e-mail: M.J.Fray@lboro.ac.uk \\ Laurence Clift \\ School of Design and Creative Arts, Loughborough University, e-mail: L.Clift@lboro.ac.uk
}

\section{ABSTRACT}

Call centre employees experience of mental game playing during work breaks were recorded in this study. The qualitative study involving two focus group discussions at different call centres, with 6 employees in one focus group and 9 in the second, stated employee's reasons for variations in the key performance metric by which they were being evaluated. In this case the key performance metric was the average speed of answer. In a previous study, where the mental games were introduced as an intervention during work breaks, the participants were asked to provide feedback on variations in productivity during a 4-week intervention study. Volunteer sampling was utilized, and the information was categorized into codes. Similar codes were grouped into themes. It was found that players are efficient in the middle of the week either because daily routine settles middle of the week or because employees try to average their metrics related to time. They also thought that productivity increased towards the end of the intervention because of games being accepted in the routine by that time, because the focus shifted from fun to work towards the end or because the employees knew they were being evaluated. According to participants, the non-players were more efficient than the players because games served as a bad distraction for the players and that players were considering games as something to do rather than an actual break. As a conclusion, it felt important to improve on the timings and frequency of the games played during work before it can be considered an effective intervention.

\section{CSS CONCEPTS}

- Human-centered computing - Social and professional topics

\section{KEYWORDS}

Mental games, work breaks, productivity, call centres, cognitive ergonomics

\section{Introduction}

This study investigates variations in key performance indicators score which were experienced by employees in an interventional study. It is a follow up study to earlier research investigating mental game playing during work breaks of call centre employees to observe the effect on the average productivity scores of employees. The average speed of answer was deemed as the most important performance metric by the call centre manager and was taken into consideration in the current research. Since call centre work involves monotony and fatigue, it was felt important to disengage the employees from routine work and involve them in a fun activity such as jigsaw puzzles, cross words, hangman, word-search and board games. This was done during their work breaks. The aim was to observe the differences in objective productivity (average speed of answer scores) when employees play the mental games and to draw suggestions considering the observed changes in objective productivity and perceived workload during the intervention. This led to the research question 'What is the potential for interventions based on mental games to influence objective productivity of call centre employees'?

Although all types of play have been recognized in the literature [1], there is still a need to see what types of play can reasonably exist at work. There is independent play, where 
one can interact with oneself only; this is called solitary play [2] and includes solving a puzzle, playing a video game, playing darts or a musical instrument at workplace. On the other hand, there is social play which includes activities such as playing football with colleagues or playing a board game with them. This study only involves mental games that do not involve screen time.

One of the most popular definition of games is provided by Suits "To play a game is to engage in activity directed towards bringing about a specific state of affairs, using only means permitted by the rules, where the rules prohibit more efficient in favour of less efficient means, and where such rules are accepted just because they make possible such activity" [푸

There are several outcomes related to play. These range from reducing fatigue [4], to reducing stress [ㅁ] , from reducing boredom [ㅁ] to increasing job satisfaction [6] . Play also helps to improve learning abilities [7] as well as help in problem solving techniques [8]. Although play has shown decrease in task performance of an employee [5, 6], it has been shown that if work tasks are considered a form of play, then employees tend to spend more time on such work tasks [9] .

There are several theories related to play in the contemporary literature. One of them is the stimulus seeking perspective of play. According to this theory, workers try to balance their workflow by finding a middle ground between becoming bored or over stimulated at work. In case of under-stimulation, individuals will try to engage themselves in play [10] and the lack of stimulation rises the urge of employees to play [11]. The flow perspective of play means that the individual attains a certain level of skill, to the extent that there is control and a feeling of automation over the concerned task [6]. The cathartic perspective of play means that the individual release their stress by managing their emotions and frustrations [11]. In this case an employee will engage in play to lower their stress levels [12]. The social and cognitive processing perspective of play [13] provides a creative aspect to play at work. It has a potential to relate work and play in a way that if an employee starts considering work tasks as part of a play, it can have a positive effect on productivity [14].

In light of the theories related to play, there are two emerging insights on play at work. One of them is the resource regulation perspective of play, which says that employees strive to conserve resources in order to overcome challenges at work. These resources can be psychosocial conditions such as team bonding, or time [15]. The other perspective is the emotion regulation of play, to which there are two perspectives [16]. The hedonic perspective highlights that employees tend to increase their level of satisfaction or decrease their level of dissatisfaction. The second perspective is the instrumental perspective, which means that even a negative emotion can be encouraged to achieve something instrumental, such as scoring high or a promotion.

Breaks that are scheduled, can have a positive outcome by adding to the emotional value of a worker and provides relief from the worker's intense work demands [17]. This relief can then have a positive effect on performance [18]. A two-session study was carried by [19] to see the effects of mid-task break and efficiency in performance, one had mentally demanding visual tasks while the other had breaks in the 2 nd and 3 rd task blocks. An improvement in performance was detected at the end of the blocks after the break. The need for taking breaks was also apparent in a study where students were asked to provide reasons for taking breaks during study. Amongst the top 10 factors, boredom came second after hunger and thirst, and lack of concentration came third. In another study, carried by [20] moderating effects were tested for work breaks to observe an association between flow at work and post work energy. It was found that work recovery and work breaks had a role in moderating the association between workflow and post work energy. This implies that it is easy to switch off mentally when easily detached from work, helping in overall recovery process.

Various ergonomic factors can affect the productivity of call centre employees. The nature of call centre work demands long sitting hours, hence call centre work is sedentary [21, 22]. There is now growing evidence that long sitting times lead to negative health effects and more focus is needed for increase in workplace interventions to reduce sitting times [23 , 24]. Health problems such as cardio-vascular diseases [25] and musculo-skeletal disorders are prevalent in work that comprise long sitting hours [26]. Poor work design and stress also has an effect on the productivity of call centre employees [27]

There are productivity measures in different call centres which are serving businesses and there is a priority for certain Key Performance Indicators in one call centre as compared to 
another one. For example, in a medical diagnostic setting, call centres have used a centralized unit to communicate the laboratory test to the clinician, via telephone. For a recommended practice, results were subject to a common metric [28]. But the monitoring and surveillance on a call centre employee has negative effects on the health of employee including emotional exhaustion [29]. In another instance, where employees of three call centres were polled, it was found that excessive surveillance and inadequate rest breaks were the two top concerns of the employees [30]. However, the loyalty of the call centre agents can be retained when key issues such as pay and benefits, training, rewards, and recognition are addressed properly [31]. Besides, play at work also helps in transfer of training/learning and an increased involvement in the job [32].

Literature has shown physical interventions in the workplace to enhance work performance, however, research on leisurely cognitive intervention is scarce. This study is part of the feedback received on a cognitive intervention (playing mental games in the work breaks such as crosswords and sudoku) being applied to sedentary workers at call centres to see if any mental stimulation takes place, taking care of the wellbeing and enhancing productivity of the worker at the same time. It is an attempt to see if leisure activities can enhance productivity in the workplace. It is intended to make a useful contribution to the evolving literature on role of mental leisure activities in the work life of an employee.

\section{Method: Study design}

This was a qualitative study based on focus group discussion. Volunteer sampling was utilized to recruit the participants. Contact centre heads in York and Leicester were identified to determine the number of employees who wanted to take part in the focus group discussions. It was requested to ideally keep equal number of employees for both groups, those who had played the games in their work breaks and those who had not. The focus group discussions were conducted in the call centre premises, in a conference room, away from workstations where the employees were working. Two focus groups were conducted from two call centre employees who participated in the interventional study, 6 members in the first group from the first call centre while 9 members in the second group, from the second call centre. The composition of the focus groups is given at table 1.

Table 1: Composition of the focus groups

\begin{tabular}{|l|c|c|c|c|}
\hline Focus groups & Players & Non-players & $\begin{array}{l}\text { Call centre } \\
\text { head/team lead }\end{array}$ & Total \\
\hline $\begin{array}{l}\text { Focus group } \\
\text { l/York }\end{array}$ & 2 & 2 & 2 & 6 \\
\hline $\begin{array}{l}\text { Focus group } \\
2 / \text { Leicester }\end{array}$ & 4 & 4 & 1 & 9 \\
\hline
\end{tabular}

Focus group 1 lasted for 1 hour and 4 minutes while Focus group 2 lasted 58 minutes. The focus groups were audio recorded. Three basic questions were asked about productivity within a broader spectrum of other questions. These were:

- Why do you think productivity is better middle day of each week for the playing group?

- Why do you think productivity is better for the players by the end of the intervention?

- People who were playing games were not as efficient as those not playing games. Why do you think so?

The focus group questions were inductive, since they were drawn from the results of the previous intervention study, where employees played games in their work breaks. The questions in the case-let, presented a broader perspective asked from the participants regarding objective productivity. They were deliberately formulated for a broad perspective, to invite as many views as possible, so that each piece of information could be placed under a theme. There were three questions, each question representing a broader theme under which there were smaller concepts, each contributing towards the theme. The method used for the questions was free listing. Sticky notes were provided to each participant after a question was being asked. They would then write the answers on the sticky notes and stick them to a whiteboard to discuss later. 
The ethical approval for the study was obtained from the Ethics approvals (human participants) sub-committee at Loughborough University. All participants participated in the study by signing a consent form and reading the participant information sheet.

\section{Results}

The analysis was carried out using QSR International NVivo 11. The three questions served to be the three themes for the answers derived from the focus group discussions. Each piece of similar information that carried similar 'meaning', 'feeling' or 'concept' was grouped under a code.

\subsection{Objective productivity}

There were 3 themes for objective productivity, emerging from the three questions about average speed of answer, as a productivity metric. The average speed of answer is defined as "the amount of time it takes to answer a typical call once it has been routed to the call centre" [33] Table 2 shows an overview of the procedure. Statements with similar meaning were placed under a single code and similar codes were then placed under a broader theme.

Table 2: Themes and codes for objective productivity

\begin{tabular}{|c|c|c|}
\hline Themes for objective productivity & Codes & $\begin{array}{l}\text { No. of } \\
\text { references } \\
\text { made }\end{array}$ \\
\hline \multirow{3}{*}{$\begin{array}{l}\text { Theme 1: Players efficient on } \\
\text { Tuesday, Wednesday }\end{array}$} & \multirow{3}{*}{$\begin{array}{l}\text { Routine is best at mid-week } \\
\text { Wrap times are averaged } \\
\text { Type of manager }\end{array}$} & 4 \\
\hline & & 4 \\
\hline & & 2 \\
\hline \multirow{4}{*}{$\begin{array}{l}\text { Theme 2: Players are efficient end } \\
\text { of intervention }\end{array}$} & \multirow{4}{*}{$\begin{array}{l}\text { Games as norm for the players } \\
\text { Fun } \\
\text { Self-conscious of being measured } \\
\text { Games help reduce tiredness }\end{array}$} & 4 \\
\hline & & 3 \\
\hline & & 2 \\
\hline & & 1 \\
\hline \multirow{4}{*}{$\begin{array}{l}\text { Theme 3: Non-players were more } \\
\text { efficient than players }\end{array}$} & \multirow{4}{*}{$\begin{array}{l}\text { Games as bad distraction } \\
\text { Nongame players got the break } \\
\text { Games players gave more details on the } \\
\text { phone } \\
\text { Extraneous variables }\end{array}$} & 5 \\
\hline & & 3 \\
\hline & & 2 \\
\hline & & 1 \\
\hline
\end{tabular}

The themes in table 2 were then broken into reasons based on personal factors, intervention factors and organizational factors acting on the productivity of employees

\subsubsection{Personal factors}

Routine is best at mid-week

When the participants were asked why they thought players were efficient middle of each week, one of the obvious responses was that the routine for efficiency builds up middle of the week. Start of the week is marked by a sluggish approach after weekend, and end of the week is the time when employees are looking forward to the weekend so middle of the week is the best for efficiency.

Participant 2: There is one point which is more prevalent is because they were over Monday blues but not yet in the weekend mentality and people are getting, this is the same thing, people are getting back in the swing of things form the weekend holiday so yeah that is one of the reasons'

Participant 1: 'Yeah I was thinking because Mondays and Fridays I'm more affected by out of work life because, if it is Monday and you are playing games, it's always Monday or a Friday whereas in the middle of the week, you have more focus on your work because it is the middle of the week so maybe playing is more effective because you are not affected by something else, if that makes sense' . 


\section{Self-conscious of being measured}

The less common reason was that by the end of the intervention, the players felt that they had played to an extent that they now need to focus on the metrics.

Participant 1: 'So they played all they could at times, so the only thing they would worry about is the stats to be improved, so they have all the games around them but they are focusing on taking the calls and improve the stats now'

Participant 9: 'More focus on stats due to the studies, so they already know that they are measured on it so they are trying to you know more conscious by the end, alright'

\section{Players gave more details on the phone}

According to employees' perception, there might have been a drop in the efficiency of the players because the games made them more engaging and they might have engaged with the customers more, hence the increase in time taken to end the call.

Participant 6: 'Maybe the people who were actually playing the games were more efficient and wrote down, I don't know, more detailed notes and they just took more time, you can't say that they were not efficient'

Participant 8: 'From talking to customer's point of view, I was thinking, workers sometimes are more likely to be jolly and engaging customer. It might be that you are efficient in a more different type of way, if you are doing admin tasks where it sounds so monotonous but if you've got to do something to interact with the customer, it's a different form of efficiency'

Figure 1 summarises the personal reasons provided by employees for the variation in the objective productivity of the employees.

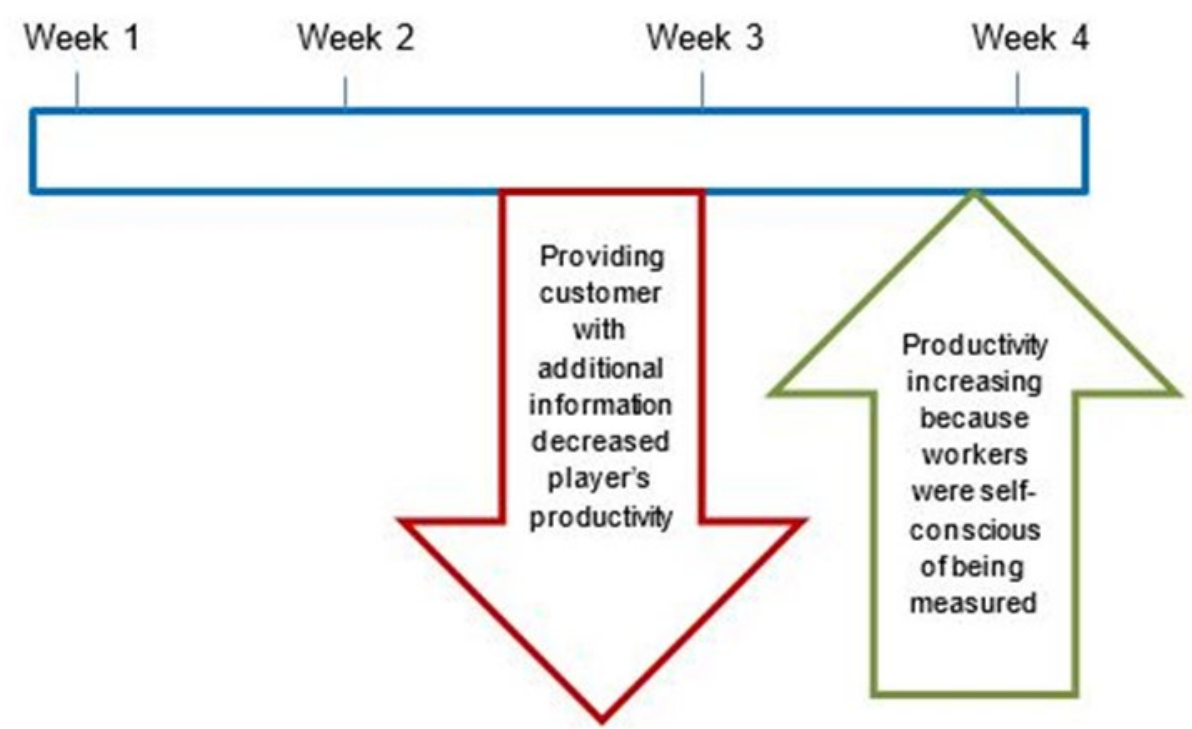

Figure 1: Employees perception of personal factors that played a role in the increase/decrease of the objective productivity during the intervention 


\subsubsection{Interventional factors}

\section{Games as norm for the players}

When participants were asked why players were efficient at the end of the intervention, the most common answer was that by the end, game playing became embedded to the routine and was considered a norm or something usual.

Participant 6: 'Yes, so it takes a while for it to bed in for the people to have it standing which is suggesting it is more permanent than it being a complete change from the next day, somebody plays the game and the next day he is more efficient, it is kind of embedding so it takes a while to show some factors building momentum'

Participant 4: 'Because they were in a routine, hmm maybe that is understandable because the first week maybe, uhhhh what is happening, second getting used to it and by the end it gets normalized.'

Fun

A second factor was that by the end, the employees started to enjoy playing the games.

Participant 2 (laughing): 'They already had the idea what the games are, they did not need to play anymore because they had already played with their friends'

Participant1: 'They got accomplished with their level of something'

Games help reduce tiredness

There was one account where a participant said that game playing also helped to reduce tiredness.

Participant 2 : 'Ya what it said in the research that helped with tiredness so I was thinking, you know, if you are less tired, ofcourse you are going to be more efficient but if.... you know you've got that bit more of energy to carry on with normal work and everything like that'

\section{Games were also bad distraction}

When participants were asked why they thought that non-players were efficient overall than the players, the most frequent reason given was that although games were fun, but it did distract from work, which did bring efficiency a bit low.

Participant 2: 'I think because they were competitive with playing games and everyone else not playing games were competitive with their work'

Participant 8: 'Because they were more competitive while playing games and not in their work.....ok so their focus is more towards playing games and not their work'.

Non-players got the break

Another reason that the participants provided was that playing games was not a break; it was a fun activity but not a restive period. They thought that the non-players had more time for rest/break.

Participant 3: 'It does make sense, if you do something else and go back, specially if you have a specific break for it, not your lunch break, a break from work, do something else but if you, but a specific so mainly you go for 10 minutes for an extra break so you need another extra 5 to 10 minutes breaks to go back to the same level of focus you had previously.... so its not good (laughter)'

Figure 2 summarises the interventional reasons provided by the employees for the variation in the objective productivity of the employees. 


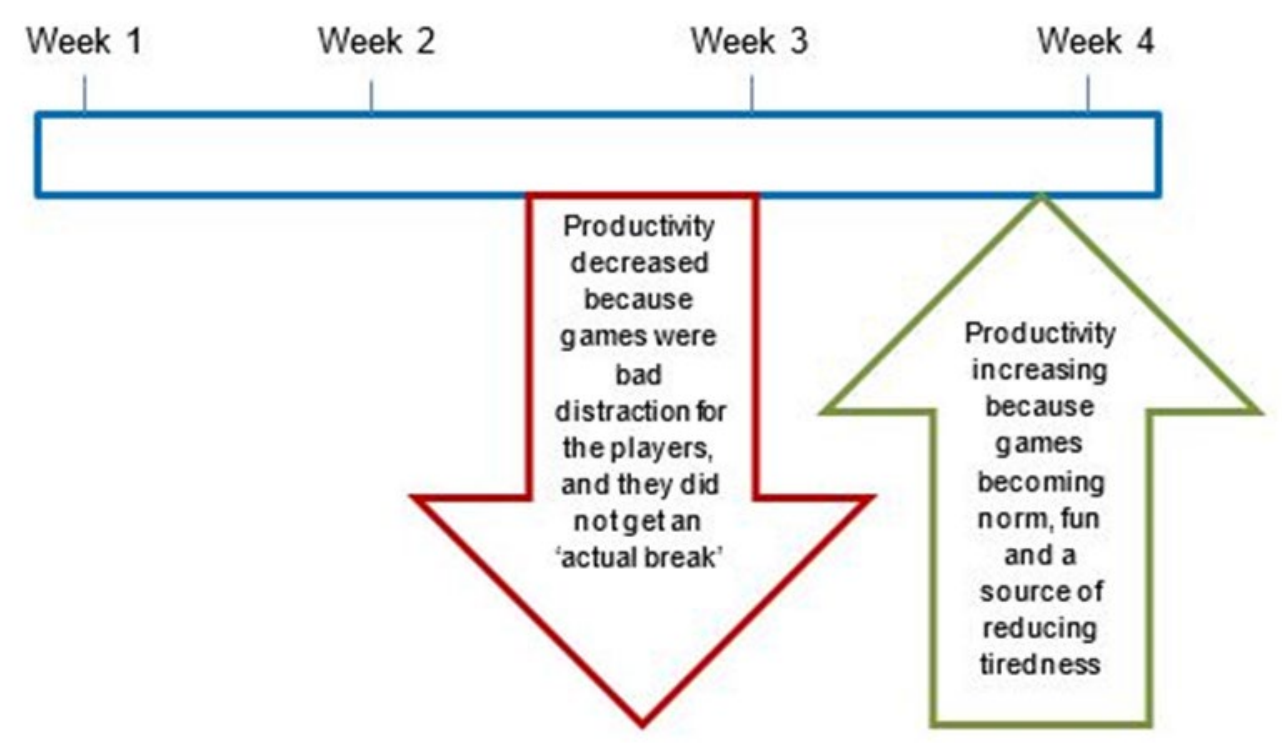

Figure 2: Employees perception of interventional factors that played a role in the increase/decrease of the objective productivity during the intervention

\subsubsection{Organizational factors}

'Wrap times' (time to call conclusion) are averaged

This meant that if an employee was not very efficient on Monday or Tuesday, he/she could work extra on another day to average out the slump in the efficiency.

Participant 4: 'So if you've got an average for a week, there is no wrap on Monday, Tuesday, Wednesday or Thursday, you can do it on Friday and improve average for the month (laughter)'

Type of manager

A less common factor was the type of manager an employee had, so if the manager knew that on Monday or Tuesday, the employee is not meeting targets, it could just ask the employees to wrap the calls quickly.

Participant 9: 'The thing is it could also be the kind of manager you choose so if you have a manager that is going around people to gather the wrap, then he tends to do that, if he sees that wrap is going longer for a person then he goes and sees that person because sometimes an employee wants to wrap but it is always talking and you can't get over that talking'

\section{Extraneous variables}

A participant even said that variables such as festive season could have affected the performance of a player as well.

Participant 10: 'So yes like throughout the day, it's not that you just play the games, they'll be more like how busy it is, what time of the year it is...so that has an effect too'

Figure 3 summarises the organizational reasons provided by the employees for the variation in the objective productivity of the employees 


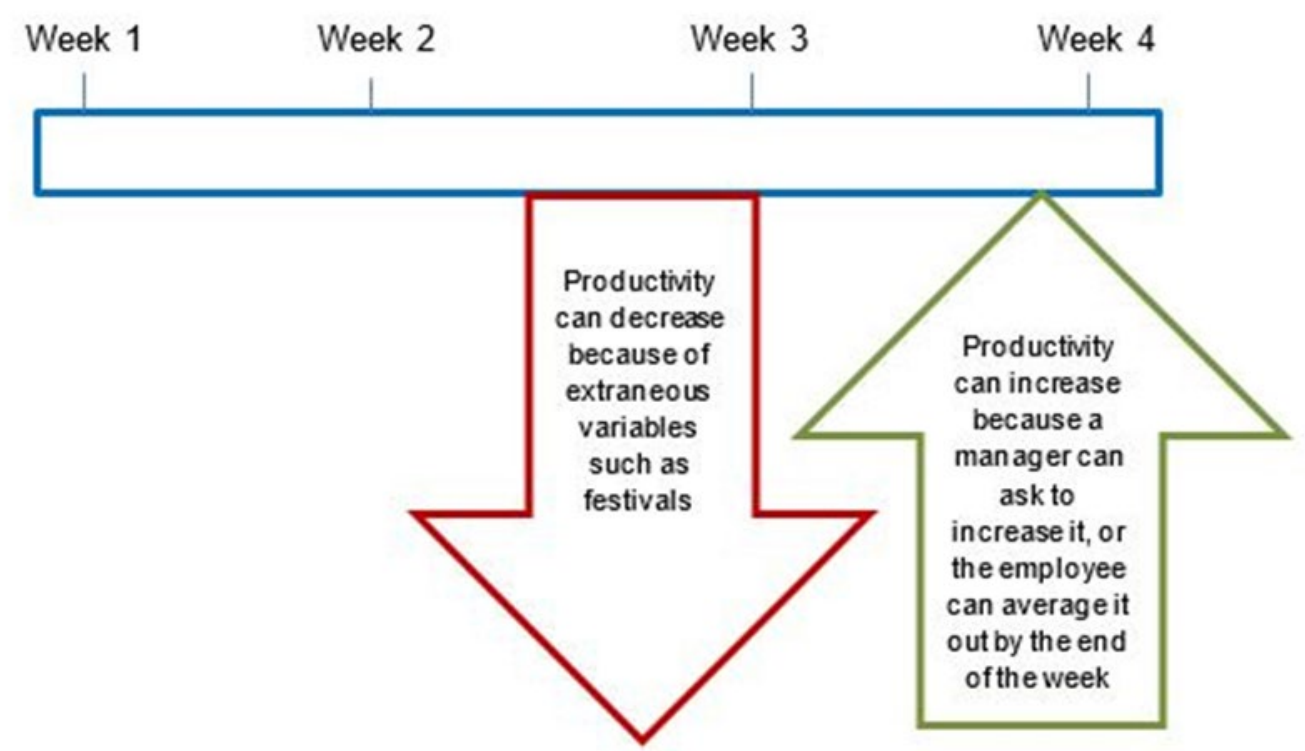

\section{Figure 3: Employees perception of organizational factors that played a role in the increase/decrease of the objective productivity during the intervention}

\section{Discussion}

In this study, it was found that productivity was highest at the end of the intervention for the playing group. If the intervention is taken as a small project, the project life cycle has four stages: initiation, execution, termination and review. The vital stages are the execution and the termination stages [34]. One can predict that because the intervention was approaching the termination stage, employees perceived that this was coming to an end and hence their focus shifted from having fun at playing games towards work. In addition, according to Mollick and Rothbard [35], consent in playing games at work have a positive effect but when consent is lacking, there could be a negative effect. It seems that the participants in the beginning or middle were lacking the consent for playing games, in other words, playing games was made mandatory. But by the end of the intervention, they had more acceptance of the games in their work routines and hence the increase in productivity.

As a second point, it was found that productivity increases in the middle of the week. Bryson and Forth [36] quotes that the average person works 360 minutes on Tuesdays and Wednesdays which is the highest as compared to other days. Flaherty and seipp-Williams [37] report that Tuesdays, Wednesdays and Thursdays represent the 'productive heart' of the workweek. Furthermore, they point that distribution of email is highest on Wednesday and this comes as the most productive day of the week. With respect to the above information, the productivity increase was according to the norm, which is middle of the week. This means that game playing was taken as a normal routine and hence an expected increase in productivity was observed middle of the week. If the comparison group is observed, its productivity is optimum on Tuesday. This could mean that they get back to work easily after Monday. It may have taken a day more for the intervention group because of the added game playing activity.

Participants thought game playing also served as bad distraction for the players. This is not a new concept because there has been a perspective that those who play can detract from their work which can greatly lead to in-efficiency [38, 39]. Nonetheless, there were times in the workweek when efficiency increased, and game playing was considered fun. 


\section{Limitations}

This study included participants from two call centres only. As with much action research, it is a time-consuming task to access organizations and employees who are willing to participate in intervention studies, since it brings some disruption to their usual work routines and can impact commercial activity. Further insight into factors affecting productivity while playing games can be made possible when more volunteer organizations can take part in similar studies.

\section{Conclusion}

It took time for the game playing routine to settle in the work life of workers, hence productivity did not increase initially. Also, games were made a mandatory activity and the playing group did not have an option of not playing the game on a workday during the intervention. Games also served as distraction from work. In light of this information, it was concluded that playing games only increased productivity at certain times in the intervention, therefore, whilst the intervention could be beneficial, the timings, frequency and mandating game playing needed careful consideration, but can further help in increasing productivity at work.

\section{Implications for further research}

From the intervention perspective, this study has practical implications. Employees stated that games became normal to their routines, it was fun playing them and reduced tiredness. This helped in increase in productivity. It is important to note that game playing activity can further be incorporated in the work design of employees in different ways to observe the effects on productivity. The approach used in this study was open questions based on focus group discussions. This approach was useful because contextual reasons could not be provided by the intervention study itself. Making sense of the earlier quantitative part was covered by this additional further study. It is interesting to note that the intervention effectiveness can improve by having a daily contact with the employees. Due to geographical proximity, it was not possible to receive feedback from employees on a daily basis, which could have improved the intervention study. Further research in this area will help organizations and policy making bodies such as IOSH (Institution of Occupational Safety and Health) re-evaluate current methods of performance measurement and formulating guidelines to improve the work life balance of employees. It provides opportunity to open avenues to questions like what kind of games do employees prefer to play in the workplace to enhance wellbeing and productivity? Or what can be the preferred timings to introduce game playing in the work routine of an employee?

\section{REFERENCES}

<bib id="bibl"><number>[1]</number> Anthony D. Pellegrini and Peter K. Smith. 1998. The Development of Play During Childhood: Forms and Possible Functions. Child psychol. psychiatr. rev. 3, 2 (May 1998), 51-57. DOI:https://doi.org/10.1017/S1360641798001476</bib>

$<$ bib id="bib2"><number $>[2]</$ number $>$ Meredith Van Vleet and Brooke C. Feeney. 2015. Young at Heart: A Perspective for Advancing Research on Play in Adulthood. Perspect Psychol Sci 10, 5 (September 2015), 639-645.

DOI:https://doi.org/10.1177/1745691615596789</bib>

<bib id="bib3"><number>[3]</number> Bernard Suits. 1978. The grasshopper: games, life, and Utopia. University of Toronto Press, Toronto; Buffalo. $</$ bib $>$

<bib id="bib4"><number>[4]</number> Carolyn Hunter, Dariusz Jemielniak, and Agnieszka Postuła. 2010. Temporal and spatial shifts within playful work. Journal of OrgChange Mgmt 23, 1 (February 2010), 87-102. DOI:https://doi.org/10.1108/09534811011017225</bib>

<bib id="bib5"><number $>[5]</$ number $>$ Bent Meier Sørensen and Sverre Spoelstra. 2012. Play at work: continuation, intervention and usurpation. Organization 19, 1 (January 2012), 81-97.

DOI: https://doi.org/10.1177/1350508411407369</bib >

<bib id="bib6"><number>[6]</number> David J. Abramis. 1990. Play in Work: Childish Hedonism or Adult Enthusiasm? American Behavioral Scientist 33, 3 (January 1990), 353-373. DOI:https://doi.org/10.1177/0002764290033003010</bib> <bib id="bib7"><number>[7]</number> Alice Y. Kolb and David A. Kolb. 2010. Learning to play, playing to learn: A case study of a ludic learning space. Journal of OrgChange Mgmt 23, 1 (February 2010), 26-50.

DOI: https://doi.org/10.1108/09534811011017199</bib>

<bib id="bib8"><number>[8]</number> Claus D. Jacobs and Matt Statler. 2006. Toward a Technology of Foolishness:

Developing Scenarios Through Serious Play. International Studies of Management \& Organization 36, 3 (October 2006), 7792. DOI:https://doi.org/10.2753/IMO0020-8825360304</bib >

<bib id="bib9"><number $>[9]</$ number $>$ Lloyd E. Sandelands. 1988. Effects of Work and Play Signals on Task Evaluation1. J Appl Social Pyschol 18, 12 (September 1988), 1032-1048. DOI:https://doi.org/10.1111/j.1559-1816.1988.tb01191.x</bib> 
<bib id="bib10"><number>[10]</number> William H. Starbuck and Jane Webster. 1991. When is play productive? Accounting, Management and Information Technologies 1, 1 (January 1991), 71-90. DoI:https://doi.org/10.1016/0959-8022(91)90013$5</ \mathrm{bib}>$

$<$ bib id="bib11"><number $>[11]</$ number $>$ Michael J. Ellis. 1973. Why people play. Prentice-Hall, Englewood Cliffs, N.J. $</$ bib $>$

$<$ bib id="bib12" ><number $>[12]</$ number $>$ Karen Dokter Des Camp and Cher C. Thomas. 1993. Buffering Nursing Stress Through Play at Work. West J Nurs Res 15, 5 (October 1993), 619-627. DOI:https://doi.org/10.1177/019394599301500508</bib> <bib id="bib13"><number>[13]</number> Eleanor Rosch. 1975. Cognitive reference points. Cognitive Psychology 7, 4 (October 1975), 532-547. DOI:https://doi.org/10.1016/0010-0285(75)90021-3</bib>

<bib id="bib14" ><number $>[14]</$ number $>$ Jane Webster and Joseph J. Martocchio. 1993. Turning Work into Play: Implications for Microcomputer Software Training. Journal of Management 19, 1 (February 1993), 127-146.

DOI : https://doi.org/10.1177/014920639301900109</bib>

<bib id="bib15"><number $>[15]</$ number $>$ Jonathon R. B. Halbesleben, Jean-Pierre Neveu, Samantha C. Paustian-Underdahl, and Mina Westman. 2014. Getting to the "COR": Understanding the Role of Resources in Conservation of Resources Theory. Journal of Management 40, 5 (July 2014), 1334-1364. DOI:https://doi.org/10.1177/0149206314527130</bib>

<bib id="bib16"><number>[16]</number> Maya Tamir, Chi-Yue Chiu, and James J. Gross. 2007. Business or pleasure? Utilitarian versus hedonic considerations in emotion regulation. Emotion 7, 3 (August 2007 ), 546-554. DOI:https://doi.org/10.1037/1528-3542.7.3.546</bib $>$

$<$ bib id="bib17" ><number $>[17]</$ number $>$ Johannes Wendsche, Andrea Lohmann-Haislah and Jürgen Wegge. 2016.

sozialpolitik.ch - Article. Retrieved December 3, 2020 from

https://www.sozialpolitik.ch/article/content/480/show/75/</bib $>$

<bib id="bib18"><number $>[18]</$ number $>$ Barbara L. Fredrickson. 2013. Positive Emotions Broaden and Build. In Advances in Experimental Social Psychology. Elsevier, 1-53. DoI:https://doi.org/10.1016/B978-0-12-407236-7.00001-2</bib>

<bib id="bib19"><number>[19]</number> Yu Sun, Julian Lim, Zhongxiang Dai, KianFoong Wong, Fumihiko Taya, Yu Chen, Junhua Li, Nitish Thakor, and Anastasios Bezerianos. 2017. The effects of a mid-task break on the brain connectome in healthy participants: A resting-state functional MRI study. NeuroImage 152, (May 2017), 19-30.

DOI:https://doi.org/10.1016/j.neuroimage.2017.02.084</bib $>$

<bib id="bib20" ><number $>[20]</$ number $>$ Evangelia Demerouti, Arnold B. Bakker, Sabine Sonnentag, and Clive J. Fullagar. 2012. Work-related flow and energy at work and at home: A study on the role of daily recovery: FLOW, ENERGY, AND RECOVERY. J. Organiz. Behav. 33, 2 (February 2012), 276-295. DOI:https://doi.org/10.1002/job.760</bib>

<bib id="bib21"><number $>[21]</$ number $>$ Alicia A. Thorp, Genevieve N. Healy, Elisabeth Winkler, Bronwyn K. Clark, Paul A. Gardiner, Neville Owen, and David W. Dunstan. 2012. Prolonged sedentary time and physical activity in workplace and non-work contexts: a cross-sectional study of office, customer service and call centre employees. Int J Behav Nutr Phys Act 9, 1 (October 2012), 128. DOI:https://doi.org/10.1186/1479-5868-9-128</bib>

$<$ bib id="bib22"><number $>[22]</$ number $>$ A. Kazi, M. Duncan, S. Clemes, and C. Haslam. 2014 . A survey of sitting time among UK employees. Occupational Medicine 64, 7 (October 2014), 497-502.

DOI:https://doi.org/10.1093/occmed/kqu099</bib>

<bib id="bib23"><number>[23]</number> Marc T. Hamilton, Genevieve N. Healy, David W. Dunstan, Theodore W. Zderic, and Neville Owen. 2008. Too little exercise and too much sitting: Inactivity physiology and the need for new recommendations on sedentary behavior. Curr Cardio Risk Rep 2, 4 (October 2008), 292. DOI:https://doi.org/10.1007/s12170-008-0054-8</bib>

<bib id="bib24"><number $>[24]</$ number $>$ Josephine Y. Chau, Hidde P. van der Ploeg, Dafna Merom, Tien Chey, and Adrian E. Bauman. 2012. Cross-sectional associations between occupational and leisure-time sitting, physical activity and obesity in working adults. Preventive Medicine 54, 3-4 (March 2012), 195-200.

DOI: https://doi.org/10.1016/j.ypmed.2011.12.020</bib $>$

$<$ bib id="bib25"><number $>[25]</$ number $>$ Birinder S. Cheema, Angelique Houridis, Lisa Busch, Verena Raschke-Cheema, Geoff W. Melville, Paul W. Marshall, Dennis Chang, Bianca Machliss, Chris Lonsdale, Julia Bowman, and Ben Colagiuri. 2013. Effect of an office worksite-based yoga program on heart rate variability: outcomes of a randomized controlled trial. BMC Complement Altern Med 13, 1 (April 2013), 82. DOI:https://doi.org/10.1186/1472-6882-13-82</bib>

<bib id="bib26"><number>[26]</number> John D. Collins and Leonard W. O'Sullivan. 2015. Musculoskeletal disorder prevalence and psychosocial risk exposures by age and gender in a cohort of office based employees in two academic institutions. International Journal of Industrial Ergonomics 46, (March 2015), 85-97.

DOI:https://doi.org/10.1016/j.ergon.2014.12.013</bib>

<bib id="bib27"><number>[27]</number> Angelina F. Mbadou and Charles Mbohwa. 2013. The impact of work design and stress on employees productivity at a call centre. International Conference on Law, Entrepreneurship and Industrial Engineering (ICLEIE'2013) April 15-16, 2013, Johannesburg (South Africa) $</$ bib $>$

<bib id="bib28"><number $>[28]</$ number $>$ Edward B. Liebow, James H. Derzon, John Fontanesi, Alessandra M. Favoretto, Rich Ann Baetz, Colleen Shaw, Pamela Thompson, Diana Mass, Robert Christenson, Paul Epner, and Susan R. Snyder. 2012.

Effectiveness of automated notification and customer service call centers for timely and accurate reporting of critical values: A laboratory medicine best practices systematic review and meta-analysis. Clinical Biochemistry 45, 13-14 (September 2012), 979-987. DOI:https://doi.org/10.1016/j.clinbiochem.2012.06.023</bib>

<bib id="bib29"><number>[29]</number> David Holman, Stephen Wood, and Chris Stride. 2005. Human resource management in call centres. Institute of Work Psychology, University of Sheffield. $\langle/ b i b\rangle$

<bib id="bib30"><number $>[30]</$ number $>$ David Holman and Sue Fernie. 2000. Can I help you? Call centres and job

satisfaction. Centrepiece. The Magazine of Economic Performance 5, 1 (2000), 2-5.</bib>

<bib id="bib31" ><number $>[31]</$ number $>$ Alan Miciak and Mike Desmarais. 2001. Benchmarking service quality performance at business-to-business and business-to-consumer call centers. Jnl of Bus \& Indus Marketing 16, 5 (September 2001 ), $340-353$. DOI:https://doi.org/10.1108/08858620110400205</bib>

<bib id="bib32"><number>[32]</number> Jane Webster and Joseph J. Martocchio. 1993. Turning Work into Play: Implications for Microcomputer Software Training. Journal of Management 19, 1 (February 1993), 127-146. DOI:https://doi.org/10.1177/014920639301900109</bib>

<bib id="bib33"><number>[33]</number> Average Speed of Answer. Call Centre Helper. Retrieved December 3, 2020 from https://www.callcentrehelper.com/average-speed-of-answer-89615.htm</bib $>$

<bib id="bib34"><number $>[34]</$ number $>$ Jeffrey K. Pinto and John E. Prescott. 1988. Variations in Critical Success Factors Over the Stages in the Project Life Cycle. Journal of Management 14, 1 (March 1988), 5-18. DOI:https://doi.org/10.1177/014920638801400102</bib $>$

<bib id="bib35"><number>[35]</number> Ethan R. Mollick and Nancy Rothbard. 2014. Mandatory Fun: Consent, Gamification and the Impact of Games at Work. Social Science Research Network, Rochester, Ny. Retrieved December 3, 2020 from https://papers.ssrn. com/abstract $=2277103</$ bib $>$

$<$ bib id="bib36"><number $>[36]</$ number $>$ Alex Bryson and John Forth. 2007. Productivity and days of the week. Discussion paper. City University of London, UK: RSA $</$ bib $>$

<bib id="bib37"><number>[37]</number> Michael G. Flaherty and Lucas Seipp-Williams. 2005. Sociotemporal Rhythms in Email: A case study. Time \& Society 14, 1 (March 2005), 39-49. DoI:https://doi.org/10.1177/0961463X05049949</bib> 
<bib id="bib38"><number>[38]</number> James D. Thompson. 2003. Organizations in action: social science bases of administrative theory. Transaction Publishers, New Brunswick, NJ. $\langle/$ bib $\rangle$

<bib id="bib39"><number $>$ [39]</number $>$ Max Weber. 2001. The Protestant ethic and the spirit of capitalism. Routledge, London; New York. $</$ bib $>$ 